\title{
Occupational Challenges and Physician Deaths During COVID-19 Pandemic
}

\author{
Md. Sahidur Rahman ${ }^{1 *(\infty)}$, Maisha Farzana ${ }^{1,2}{ }^{(}$Tazrina Rahman $^{1,3}{ }^{\circledR}$ \\ ${ }^{1}$ Department of Research and Innovation, One Health Center for Research and Action, Akbarshah, Chattogram-4207, \\ Bangladesh \\ ${ }^{2}$ Asian University for Women, Chattogram, Bangladesh \\ ${ }^{3}$ Chattogram Medical College Hospital, Chawkbazar, Chattogram-4203, Bangladesh
}

Corresponding Author: Md. Sahidur Rahman, DVM, MPH, Coordinator, Department of Research and Innovation, One Health Center for Research and Action, Akbarshah, Chattogram-4207, Bangladesh. Tel: +880-1705 727081, Email: sahid. dvm@gmail.com

Received December 28, 2020; Accepted January 4, 2021; Online Published January 6, 2021

Citation: Rahman MS, Farzana M, Rahman T. Occupational challenges and physician deaths during COVID-19 pandemic. Int J Travel Med Glob Health. 2021;9(2):100-101. doi:10.34172/ijtmgh.2021.16.

\section{Dear Editor,}

Coronavirus disease 2019 (COVID-19) cases have rapidly expanded across the world since its first case which was detected in Wuhan, China in December 2019. Globally, about 69521294 confirmed cases and 1582674 deaths have been reported till December 12, 2020. ${ }^{1}$ In Bangladesh, the first three COVID-19 cases were confirmed on March 8, 2020. Since then, cases have been rising, and by 12 th December, a total of 489178 confirmed cases have been reported with 7020 deaths. ${ }^{2}$

Health care providers (HCPs) all over the world are the most vulnerable group to the coronavirus infection as frontline fighters. In Bangladesh, the situation is poorer, as about 80000 registered doctors out of 100000 are dealing with COVID-19 patients as frontline fighters ${ }^{3}$ as the total workforce was not divided by a plan to combat this pandemic situation. In addition to shortage, intensive care units (ICUs) had not raised standards for treating COVID-19 patients and many hospitals were not equipped with a central oxygen line. ${ }^{4}$ These accelerate the early death of patients and infection to HCPs in Bangladesh. Lack of negative air pressure in isolation units and ICUs causes the spread of infected aerosols to HCP while providing services to admitted patients. A continuous 12 hour-work time, as opposed to the usual eight hours, creates a physical and mental strain on healthcare providers during the time of the pandemic. A young doctor in China died of a heart attack resulting from continuous work of 10 days. ${ }^{5}$

The people hiding COVID-like symptoms and infection due to the stigma while visiting doctors' chambers or hospitals to seek medical care put the doctors and other health care workers at great risks. At least 12 health workers, including five doctors, of a tertiary care hospital in Dhaka were infected with the coronavirus because of performing surgery on a COVID-19 positive patient. $^{6}$ Moreover, they experience avoidance from their community members and maltreatment from house owners due to unusual fear and stresses posed by the pandemic, leading to an increasing number of deaths of doctors and undermining the confidence level in doctors and healthcare providers in Bangladesh. In Bangladesh, the first death of a doctor (47 years) from COVID-19 was reported on April 15. ${ }^{7}$

According to the Indian Medical Association, the risk of death by COVID-19 is 17 times higher in doctors and 15 times more in healthcare workers. ${ }^{8}$ In the United States, healthcare providers are nearly 12 times more likely to test positive for the COVID-19 than the general population. ${ }^{9}$ In Bangladesh, the death rate of doctors was $4 \%$, which was higher than the average standard mortality rate of $2.5 \%$ around the world.? The Bangladesh Medical Association (BMA) reported that, as of December 12, a total of 8135 healthcare providers, including 2881 physicians, 1973 nurses, and 3281 other health care staffers were infected with the COVID-19. Bangladesh witnessed the death of 113 registered doctors ${ }^{10}$ and the death toll of these frontline fighters is rising as the COVID-19 pandemic is persisting longer. Therefore, a collaborative action should be taken to ensure workplace safety, adequate personal protective equipments, and proper training facilities to all healthcare providers to curb the infection and death rate among them.

\section{Authors' Contributions}

All the authors contributed equally to this study.

Copyright ( $\odot 2021$ The Author(s). This is an open-access article distributed under the terms of the Creative Commons Attribution License (http:// creativecommons.org/licenses/by/4.0), which permits unrestricted use, distribution, and reproduction in any medium, provided the original work is properly cited. 


\section{Conflict of Interest Disclosures}

The authors declare that he has no conflict of interest.

\section{Ethical Approval}

Not applicable.

\section{Funding/Support}

None.

\section{Acknowledgements}

The authors like to thank Nazifa Rafa for proofreading the article.

\section{References}

1. World Health Organization (WHO). WHO Coronavirus Disease (COVID-19) Dashboard. WHO; 2020. Accessed October 30, 2020. https://covid19.who.int/.

2. Directorate General of Health Services (DGHS). COVID-19 Dashboard. http://dashboard.dghs.gov.bd/webportal/pages/covid19.php. Accessed October 30, 2020.

3. Arab News. Bangladesh Loses Doctors to COVID-19. https:// www.arabnews.com/node/1689996/world. Accessed October 29, 2020. Published 2020

4. The Daily Star. Editorial: Why is it Taking so Long to Make ICUs Functional? The Daily Star. April 30, 2020. https://www. thedailystar.net/editorial/news/why-it-taking-so-long-makeicus-functional-1897951.

5. The Independent. Coronavirus Doctor Dies of Heart Attack
After Working 10 Days Straight. The Independent. February 6, 2020. https://www.independent.co.uk/news/world/asia/ coronavirus-doctor-dies-china-song-yingjie-hunan-heartattack-a9321946.html.

6. bdnews24.com. Health Minister Says 80pc COVID-19 Cases Don't Need Treatment, Urges Patients Not to Hide Info. https:// bdnews24.com/bangladesh/2020/04/17/health-minister-says80pc-covid-19-cases-dont-need-treatment-urges-patients-notto-hide-info. Published 2020.

7. Dhaka Tribune. Bangladesh Sees 100th Death of Doctors from Covid-19. https://www.dhakatribune.com/health/ coronavirus/2020/10/15/bangladesh-sees-100th-death-ofdoctors-from-covid-19. Published 2020.

8. Deccan Chronicle. Death Due to Coronavirus Higher Among Doctors, Healthcare Workers. https://www.deccanchronicle. com/nation/current-affairs/110920/death-due-to-coronavirushigher-among-doctors-healthcare-workers.html. Published 2020.

9. CNBC. Coronavirus: Health workers around the world share stories from the front lines as deaths surpass 1 million. https:// www.cnbc.com/2020/09/29/coronavirus-health-workersstories-from-front-lines.html. Accessed October 30, 2020. Published 2020

10. The New Nation. Only One Among 113 Dead Medical Frontliners Gets Compensation. http://m.thedailynewnation. com/news/271788/only-one-among-113-dead-medicalfrontliners--gets-compensation. Published 2020. 